\title{
Examining Gender Representation in an Indonesian EFL Textbook
}

\section{`Zango Anisa Agni ${ }^{1}$, Endang Setyaningsih², Teguh Sarosa ${ }^{3}$}

Sebelas Maret University ${ }^{1,2,3}$

Address: Jl. Ir. Sutami No.36, Kentingan, Jebres, Surakarta, Jawa Tengah, Indonesia ${ }^{1,2,3}$

E-mail: zangooagni@gmail.com¹, endangsetyaningsih@staff.uns.ac.id 2, teguhsrs@staff.uns.ac.id ${ }^{3}$

Corresponding Author*

DOI: https://doi.org/10.18326/rgt.v13i1.183-207

\section{Submission Track:}

Received: $10-04-2020$

Final Revision: 23-05-2020

Available online: $01-06-2020$

\begin{abstract}
Considering its influential role in students' behavior and attitudes, a textbook has to reflect balanced images, and information about males and females. It also has to support broad choices and many roles for both sexes to avoid unjust or bias gender issues. This study aimed at examining whether an EFL textbook published by the Indonesian government promotes gender equity by (1) mapping the proportion of textual and visual representation of
\end{abstract}


males and females in the textbook; (2) describing how males and females are treated in the textbook. Through content analysis, the study revealed that the book is gender-biased as indicated from unbalanced (1) textual and visual representation (2) variety of activity, role, and occupation, (3) order of mention, and (4) adjectival portrayal. In all indicators, the female is underrepresented, hidden, and framed within traditional gender stereotyping. Reflecting on these findings, revision by the government and/ or careful treatment by teachers when using the book are ushered.

Keywords: bias, content analysis, gender representation, gender stereotype, textbook.

\section{INTRODUCTION}

Dakar convention which was held by the United Nations of Educational, Scientific, and Cultural Organization (UNESCO) in Senegal 2000 and its follow up event in 2015, recommended that awareness of political correctness of gender issues need to be forced in teaching and learning tools and materials. The initial evaluation of gender representation is the study by Lakoff in 1973 . Lakoff's study revealed that women tend to be in a lower status position more than men. This finding has attracted scholars around the world to conduct studies about gender including its representation in textbooks. Textbook serves as one of the sources of language input for students and as a basis for language learning in class (Tomlison, 1998). Along these lines, it is significant that textbook needs to reflect balanced pictures, data concerning males and females and support wide choices and numerous roles for both genders for avoiding unjust or bias gender issue. However, Lee (2014) noted that gender bias is still founded in textbooks. This can influence students' thinking about men and women. Lee (2014) also said that material found in textbooks invites.learners 
to relate to character conduct in the textbooks, which makes students imitate practices that are regular of their genders. Thus, gender has to be presented equally in textbook because textbook has an important role that influences students' behavior and attitudes towards gender. This present study focuses on senior high school ELT textbook, it highlights a single book published by the Indonesian Ministry of Education and Culture, "Bahasa Inggris". The study expands the scope of investigation by counting the appearance of male and female both in textual and visual, and examining how male and female are treated in the textbook. This examination is carried out by looking at the order of gender appearance and the gender's domain activity, role, and occupation, and adjective used by male and female.

\section{Gender Representation and Gender Stereotype in ELT Textbook}

Gender is the role of female and male that has been constructed up by social and cultural (Holmes, 2007). It is a contextual dependent term that applies to males and females with specific linguistic strategies (Bell, McCarthy \& McNamara, 2006). Meanwhile, the word 'representation' is the production of meaning through language (Hall, 1997). In addition, Shorter Oxford Dictionary in Hall (1997) stated that 'to represent' means to describe or depict it, to call it up in the mind by portrayal or description or imagination. Thus, gender representation means how the role of males and females which build socially is described.

Movements to gender equity has been running for decades and today more and more individuals as well as organization voice their thoughts on the issue. The UNESCO, for example, have sounded for males and females to have 
equal access in education and learning opportunities. Likewise, LeMoyne (2011) noted that gender equity implies that males and females have the same rights, resources, possibilities, and protections. In a broader sense, EDC (2007) stated that gender equity deals with the ability of female and male to have same opportunities, rights, and responsibilities in aspects of life.

Regardless of growing the gender sensitive movement, traditional gender stereotyping persists today. According to Matsumoto and Juang (2008) gender stereotypes are behavioral or psychological characteristics of males or females. In Indonesia, gender stereotype is still an issue. There is gender stereotype that is reflected in gender roles. Some people still have a traditional perspective of three ur; sumur, dapur, and kasur (wash up, work in the kitchen, and bed) as the duty of females. Whereas now, females do not only relate to those activities, but they also work outside as male commonly do (Damayanti, 2014). Sunderland, 1994a in Mustapha (2012) also mentioned some dimensions of gender stereotype/sexism, those are; invisibility, occupational stereotype, and relationship stereotype, namely: (1) Invisibility: The visibilities of females are less than males or vice versa, (2) Occupational stereotypes: females or males are represented fewer in occupational roles, (3) Relationship stereotypes: while females mostly are represented as individual being more in relation with males, rather than males more relation with females, (4) Personal characteristic stereotyping: while females represented as emotional and timid, (5) Disempowering discourse roles: when more males talking first rather than females, (6) Degradation: blatant sexism to the point of misogamy.

Ignoring its sensitivity, gender is one of the elements that is often taken for granted in ELT textbooks. It is common to find ELT textbooks which are biased in representing males and females; while, ideally, the textbooks should depict a balance of active roles between males and females. 
REGISTER JOURNAL

Vol. 13, No. 1, (2020), pp.183-207

p-ISSN: 1979-8903; e-ISSN : 2503-040X

Website: http://journalregister.iainsalatiga.ac.id/index.php/register/

In Indonesia, the study of gender representtaion had been conducted by Yonata and Mujiyanto (2017) and Fahriany (2019). In Asia, the study of gender representation also had been conducted by some researchers, i. e. Nofal And Qawar (2015), Salami and Ghajarieh (2016), Dahmardeh and Kim (2019), etc. In addition, Lee had been conducted some studies of gender representation in different years.Lee had conducted several researches about gender representation in 1999, 2008, 2009, 2010, 2012, 2014, and 2016. In the latest research, Lee (2016) investigated gender representation in four contemporary Japanese EFL textbooks for High School in Japan which titled "Gender representation in Japanese EFL textbooks - a corpus study". The result of this study reveals that female is underrepresented in some aspects, such as female under-representation in the appearances, the adjective used, and the order of mention. While in the gender-neutral and gender marked vocabulary, the four EFL textbooks use gender-neutral vocabulary. Besides, Dahmardeh and Kim in 2019 investigated gender representation in five ELT textbook for secondary school in Iran titled "Gender Representation in Iranian English Language Coursebook". The result of this study is there is gender imbalance in these five ELT textbooks. Male is more presented than female in names and photo. Also, the role of males is more wide and varied. Moreover, Qatawneh and Rawashdeh (2019) examined a study entitled "Gender representation in the Arabic language textbook for the ninth grade approved by the Ministry of Education for use in schools in the United Arab Emirates (UAE)". The study reveals a significant difference between the total number of aspects presented for females compared to males, which means that there are imbalances and clear differences in the representation of gender aspects in this textbook. Also, 
when female and male appears in a single phrase, males are mentioned before females. Moreover, the study also reveals that the language used in the textbook was mostly in favor of males.

\section{RESEARCH METHOD}

The object of this study is an English language textbook for tenth-grade Senior High School student titled "Bahasa Inggris" published by the Indonesia Ministry of Education and Culture. This book is used by almost all of senior high schools in Indonesia. In this study, we employed a content analysis as the research design. Referring to Krippendorff (2004), content analysis is a research technique for making valid and replicable inferences from texts (or other meaningful matter) to the contents of their uses. In conducting the content analysis, categories for analysis were pre-developed from Porreca (1984), Lee (2014), and Qatawneh and Rawashdeh (2019), and it covered 11 aspects. 


\section{Table 1. Research Instrument}

\begin{tabular}{|c|c|c|c|}
\hline R.Q. & Categories & Criteria & Codes \\
\hline \multirow[t]{5}{*}{$\begin{array}{l}\text { 1. How are male and } \\
\text { female represented } \\
\text { in the textbook? }\end{array}$} & $\begin{array}{l}\text { Female and } \\
\text { Male } \\
\text { appearance }\end{array}$ & $\begin{array}{l}\text { 1. Frequency of selected gendered } \\
\text { words (e.g. wife, husband, girl, } \\
\text { boy, man, woman, etc.) }\end{array}$ & $\begin{array}{l}\text { GWm } \\
\text { (male), } \\
\text { GWf } \\
\text { (female) }\end{array}$ \\
\hline & & $\begin{array}{l}\text { 2. Frequency of occurrence of } \\
\text { feminine and masculine proper } \\
\text { noun }\end{array}$ & $\begin{array}{l}\text { PFm, PFf, } \\
\text { NPFm, } \\
\text { NPFf }\end{array}$ \\
\hline & & $\begin{array}{l}\text { 3. Frequency of occurrence of } \\
\text { feminine pronouns and masculine } \\
\text { pronouns }\end{array}$ & $\begin{array}{l}\mathrm{Pm} \\
\mathrm{Pf}\end{array}$ \\
\hline & & $\begin{array}{l}\text { 4. Frequency of occurrence of female } \\
\text { and male address titles }\end{array}$ & $\begin{array}{l}\text { ATm } \\
\text { ATf }\end{array}$ \\
\hline & & $\begin{array}{l}\text { 5. Frequency of occurrence of female } \\
\text { and male character in } \\
\text { illustration/images }\end{array}$ & $\begin{array}{l}\text { Vgm, Vgf, } \\
\text { Vim, Vif, } \\
\text { Vn }\end{array}$ \\
\hline
\end{tabular}

2. How are

male and

female

treated in the

textbook?
Female and

Male activity,

role and

occupation

Frequency of female and male activity, role and occupation according to the aspects:

1. Educational aspect: Everything related to education and its multiple activities.

2. Professional aspects: Everything related to the professions, business, industry, science, engineering such as medicine nursing, employment, maintenance, and others.

3. Social and family aspects: All aspects related to family, social cooperation, and deepening the spirit of national belonging.

$\mathrm{Sfa} / \mathrm{rm}$

$\mathrm{Sfa} / \mathrm{rf}$ 
4. Leisure aspects : All aspects related to an activity in a leisure time, such as listening to music, game, and others

$\begin{array}{lll}\text { Order } & \text { of } & \begin{array}{l}\text { Order of mention of male and female in a } \\ \text { phrase coordinated by and/or }\end{array} \\ \text { Mention } & & \text { Om } \\ & & \text { Of }\end{array}$

$\begin{array}{llll} & \text { Adjectives collocating with selected } & \text { Ap m } \\ \text { Adjective used } & \begin{array}{l}\text { gendered nouns or their plural forms } \\ \text { (woman, man, boy and girl), and the An m } \\ \text { pronouns he and she }\end{array} & \end{array}$

Adapted from Porreca (1984), Lee (2014), and Qatawneh and Rawashdeh (2019).

The technique of data collection which the researcher employ was document analysis. Then, data obtained were analyzed following the seven steps of analytic procedure listed in Marshall and Rossman (2006, p. 156-157).

1. Organizing the data

All the data were examined through open coding to make it more organized. Open coding done by reading through data several times and then starting to create tentative labels for chunks of data. The data were analyzed every sentence, and even word by word. This process aimed to build concepts and categories.

2. Immersion in the data (by reading and re-reading)

The data were read and re-read to find the structure for further categories generation. 
3. Generating categories

Based on the immersion, there were other two emerging categories. There were nine pre-developed aspect; (1) frequency of selected gendered words, (2) frequency of occurrence of female and pronouns, (3) frequency of occurrence of female and male address titles, (4) frequency of occurrence of female and male character in illustration/images, (5) kinds of female and male activity, role and occupation according to some aspects such as (a)educational, (b) professional, (c) social and family, (6) the order of mention of male and female in a phrase coordinated by and/or, (7) and adjectives collocating with selected gendered nouns and their plural form. Then, the two emerging categories are frequency of occurrence of female and male proper nouns and kinds of female and male activity, role, and occupation in leisure aspect.

4. Coding the data

The data were coded based on the 11 aspects. Tables were made for each aspect. Then, the frequency of each aspect were counted using tally. Then, tally is given in each category (male/female) in the table of each aspect. Besides, kinds of adjectives used were listed and the number of each adjective used were counted, and also kinds of activity, role, and occupation in educational, professional, social \& family, and leisure aspect were also listed then put in the table. Besides, to make it easier, sign in every taken data were given in the textbook. 
5. Interpreting the data

After the data were coded, the data were interpreted. The coded data were summarized, then reviewed for patterns and relationships, and related the results to data obtained from the inter-rater reliability.

6. Searching for alternative understanding

Alternative explanations as well as alternative point of view for particular data were looked for. Basic theory, data's inter-rater, and previous study were read and learned.

7. Writing the report

After the sufficient understanding was gained, the report was written.

To check the reliability, an experienced English teacher who has been using the textbook served as an inter-rater. To ensure the inter-rater reliability, Kappa coefficient calculation was carried out using SPSS 17. The result is 0.798. Based on Landis and Koch (1977), Kappa value of more than 0.75 is indicated as excellent reliability. Thus, it can be interpreted that the inter-rater realibility of this study is excellent. 


\section{RESULTS \& DISCUSSION}

\section{How male and female are represented in the textbook}

\section{Textual Representation}

In terms of textual representation, there are four aspects that are analyzed, namely frequency of selected gendered word, frequency of proper noun, frequency of pronoun, and frequency of address titles.

Table 2. Frequency of male and female in textual representation

\begin{tabular}{|c|c|c|c|}
\hline \multicolumn{2}{|l|}{ Male } & \multicolumn{2}{|c|}{ Female } \\
\hline Aspect & Frequency & Aspect & Frequency \\
\hline $\begin{array}{l}\text { Gendered } \\
\text { words }\end{array}$ & 132 & $\begin{array}{l}\text { Gendered } \\
\text { words }\end{array}$ & 160 \\
\hline Proper noun & 448 & Proper noun & 299 \\
\hline - Public figure & 165 & - Public figure & 52 \\
\hline - Non Public & 283 & -Non Public & 247 \\
\hline Figure & & Figure & \\
\hline Pronoun & 379 & Pronoun & 327 \\
\hline Address titles & 5 & Address titles & 1 \\
\hline Total: $964(55 \%)$ & & Total: $787(45 \%)$ & \\
\hline
\end{tabular}

Table 2 shows the frequency of male and female's freuencies in textual representation.

1) Frequency of selected gendered words

As shown in table 2, the frequency of females in the form of gendered words outnumbers the males. However, the variety of female words is less than male words. In addition, in some of narrative texts, the animal characters such as "kanchil" and "crocodile" are indicated as male, as shown 
in the use of masculine pronouns (he, his, and him). Thus, it can be concluded that males hold more varied roles and status than females in the textbook examined.

2) Frequency of male and female proper noun

In the textbook examined, there are six texts related to male-oriented issues. In addition, in some chapters of the textbook examined, there are quotations from some public figures at the end of most chapters. Based on table 1 , the frequency of males in terms of proper nouns is higher than females. The proper noun is categorized into two categories, such as public figures and non-public figures. In both categories, the proportion of males is higher than females. There are 11 quotations in the textbook examined; 10 out of 11 are from male figures. Thus, it could be a reflection of male dominance in power. In addition, it can be inferred that male is more influential than female.

3) Frequency of male and female pronoun

As shown in table 2, the representation of male pronouns in all types of pronouns is higher than female pronouns

4) Frequency of male and female address titles

Table 2 shows that the frequency of female address titles is less than male address titles. In the textbook examined, the use of male title occurred frequently, while female title occurred much less in frequency. It is surprising to note here that only one female called by the title, i.e., 'Mrs. Sabariah. Other than 'Mrs.' no female title was used in the textbook. In.comparison, male title was repeatedly used in the textbook as 'Mr. Sultoni', 'Mr. Surya', and Mr. Muslih'. This also shows biased and unequal representations of female and male genders. 
From the the presentation of data, it can be concluded that male is more presented textually in the textbook. This phenomenon is known as invisibility. Invisibility occurs when the visibilities of females are less than males or vice versa (Sunderland in Mustapha (2012)). Sadker et al (1991) stated that invisibility is the most dangerous bias. When the visibility of male and female are not represented equally in textbook, it could lead the students to have a wrong perception about gender. The female's invisibility in the textbook could mean that female is not considered as significant and worthy. Lee (2006) stresses that under-representing females indirectly convey that females and their achievements are not worthy. Like other studied textbooks around the world, females tend to be treated unfairly in such a way in this case. Moreover, Tarrayo (2014) stated that if females are not cited as oft as males in textbooks, the implicit signals are that females are not significant enough to be included in those textbooks.

\section{Visual Representation}

In terms of visual representation, images or pictures in the textbook examined are analyzed. In determining whether the picture is female or male, we see the context.

Table 3. Frequency of male and female in visual representation

\begin{tabular}{lccclc}
\hline & Male & & \multicolumn{2}{c}{ Female } & \multicolumn{2}{c}{$\begin{array}{c}\text { Neutral (male \& } \\
\text { female) }\end{array}$} \\
\hline Individu & 16 & Individu & 6 & Group & 12 \\
Group & 12 & Group & 5 & &
\end{tabular}


Table 3 shows the frequency of male and female in visual representation. Table 3 reveals that males representation in both individual and group images is higher than females images. In addition, the neutral images that consist of males and females in 1 frame were also under the representation of male images. In a nutshell, the achieved findings stressed on the inequality between females and males. The female's portion to males is about 1 to 3 . In another word, males are represented exceed twofold comparing females. A study by Ahmad and Shah (2019) also revealed that in their textbook examined male dominance is quite visible in the pictorial representation.

\section{How male and female are treated}

\section{Kinds of activity, roles, and occupation of male and female in the textbook}

In this section, kinds of activity, roles, and occupation of males and females are analyzed based on four aspects, namely educational aspect, professional aspect, social $\&$ family aspect, and leisure aspect.

1) Educational aspect

In educational aspect, the activities of males was more varied than females. It was related to the level of education and field of study. Males were represented having activity on some level of education such as elementary school, vocational school, high school, and higher level of education while female was only represented on higher level of education. In addition, males were represented studying in some field of studies such as language and engineering, while female was represented studying in culinary. The activities of females were also related to teaching. However, 
both males and females were represented having the same activity in competitions, i.e won speech contest and math olympiad for female, and won speech contest for male.

2) Professional aspect

Male's activity, role, and occupation is more various than female in professional aspect. It shows that male has more chance to work in various field than female. Males are represented working and doing activity related to engineering, business, and industry. While female is not represented having role or activity related to engineering, business, and industry. While female is not represented having role or activity related to engineering, business, and industry. Other than that, female's roles and occupations tend to relate with culinary and health like baker, medical doctor, and the activity is make and sell a snack in the canteen. However, in this textbook, both males and females are represented equally with the role of both genders as a teacher, leader and flight attendant. It indicates both males and females could have the same role.

3) Social and family aspect

In the textbook examined, female's activity in social \& family aspects is more varied than males. From these lists of activities in social \& family aspect, female is suggested to do domestic activities such as dealing with home-related activities. This result is also supported by Wu and Liu (2015) who argue that women are depicted more in the category of domestic activities in which they undertake all the housework and perpetuate nursing and caring family. However, males and females are represented equally in family roles. However, both males and females are represented by having the same family roles. It is in line with the previous studies of Lee and Collins's 
(2008) and Yang's (2011) who find the fairly equal representation of both genders in familial settings: both male and female are represented as father and mother, husband and wife, and son and daughter.

4) Leisure aspect

Male's activity in leisure aspect is more varied than females, but the activities and role of female are also various. Female is represented in the textbook by doing some activities, such as play basketball and go to gym and having role as football supporter which are commonly known as male activities and role. In addition, male and female activities mostly were included as outdoor activity, except one of activities of female i.e practice baking cookies.

From the findings, it can be concluded that male's activity, role, and occupation are more varied than females. It is also known as occupational stereotyping. It occurs when females or males are represented fewer in occupational roles (Sunderland in Mustapha (2012)). Huang in Wu and Liu (2015) stated that the occupational role represented by females and males in textbooks had a role as models for students and can influence the life aspiration of students. Thus, it is problematic because in the textbook female is represented having limited occupational roles than male. Limiting female to do some kinds of activity and role also shows that females are less competent than males.

\section{Order of Mention}

Table 4. Order of mention

\begin{tabular}{cc}
\hline Male & Female \\
\hline $56(84 \%)$ & $11(16 \%)$ \\
\hline
\end{tabular}


Table 4 shows the order of mention of male and female in the textbook. In this textbook, male dominance and superiority are shown by mentioning males before females in one single phrase. As in previous study (e.g. Lee (2014), (2016); Lee and Collins (2008), (2009); Porreca (1984); Qatawneh and Rawshdeh (2019)), the present study reveals the textbook contains male firstness over than female firstness. As shown in table 4.11, there is a clear tendency for assigning firstness to males. There are 56 male firstnesses in the textbook, however there are only 54 male firstnesses that indicate as stereotype. It is because the male firstness "Habibie and his wife" does not show any stereotype as the phrases included in the authentic text entitled "B.J. Habibie" in the textbook. Thus, the author tend to mention Habibie first, then continued by "his wife", rather than "His wife and Habibie" because the text is about "B.J. Habibie" not "Habibie's wife". Lee (2014) stated that the way of putting female names after male names in coordinated expressions also conveys an implication of female inferiority. Besides, Ahmad and Shah (2019) said that the one who is mentioned first before another one is given more worth. Thus, it indicates that in this textbook male is worthier than female.

\section{Adjective used by males and females}

The kind and frequency of adjectives used by males in the textbook examined were also higher than females. In addition, there is a gender stereotype related to the adjective used. In this textbook, the author tended to represent female by using adjectives related to their emotions, age, and appearance. At the same time, male is represented by using adjectives related to physical and mental strength and also wealth. United Nations of Human 
Rights (2014) stated that gender stereotypes can be both positive and negative. In this textbook, females are represented using negative adjectives higher than males. It indicates that females having negative attitudes higher than males. While males were represented using positive adjectives higher than females. It indicates that males having positive attitudes higher than females.

All in all, it clearly shows that there is still gender bias in the textbook. Biased representation of both genders could negatively affect learners. Foroutan (2012) stated that if there are gender inequalities in textbooks that are authored and simulated by students, they will likely be socialized into various gender roles, resulting in the perpetuation of inequalities and bias against women. This may result in them failing to realize their potential (Amerian \& Esmaili, 2015). Because of the negative effects of gender bias in the textbook, efforts should be made to represent both genders in equal proportion. For example, textbook adoption committees should be formed to assess the factual coverage of race, class, and gender in the textbooks. In addition, wherever textbooks fail to ensure equal representation of the gender, the teachers should supplement the material to balance the coverage of both genders by themselves (Chick, 2006).

\section{CONCLUSION}

The study confirms that EFL textbook which tends to represent male and female unequally is biased, particularly the EFL textbook titled "Bahasa Inggris" for tenth-grade Senior High School students published by Indonesian Ministry of Education in 2018, therefore it needs to be treated with caution.

There are unequal representations of both genders. In the textbook, the appearance of females both in textual and visual are less represented than male. In textual representation, male outnumbers female in terms of the frequency of 
gendered word, proper noun, pronoun, and address titles, and also male plays dominance in the quality as shown in the number of quotation from male figures. It indicates that male is having more status/roles and also male is considered more influential as indicated by the number of quotation in the textbook. In addition, male also outnumbers females in visual representation by $33 \%$. Lee (2006) stresses that under-representing females indirectly convey that females and their achievements are not worthy.

Besides, kinds of activities, roles, and occupations of female are also limited, while male is represented as having more various activities and roles than female in all gender aspects, i.e educational, professional, and leisure. Whereas female's activity in social \& family aspects is more various than male, it indicates that female is mostly presented to do domestic roles. A clear bias can be seen in the educational and professional aspects. In educational aspects, male is represented having various activities in some level of education and field of study while female is only represented having activity in one level of education and culinary. In professional aspects, male is represented having various activities and roles. Moreover, in this textbook, male's activity, role, and occupation are related to science, engineering, business, and industry, while female's activities and roles are related to culinary and health.

In addition, pattern of mentioning both genders in one phrase is also showing bias when males were mentioned before females. Moreover, the use of positive adjectives by male is higher than females, while the use of negative adjectives by female is higher than males. It indicates that female in the textbook is represented having more bad attitudes than male. Moreover, there is a tendency to represent females in terms of their age, appearance and 
emotions. On the other hand, the textbook's authors tended to represent males with physical, mental strength and wealth.

There are some suggestions from the researcher, namely (1) textbook authors need to avoid gender stereotyping and inequality in providing adequate and proper textbooks as main source material for English teaching and learning process. It could be done by asking some reviewers to check, review, and make sure that the textbook contains gender equality, (2) teachers as the main actor in the classroom can manage to equalize gender stereotype through selecting appropriate materials. Besides, the textbook used is contained gender stereotypes, it is better for the teacher to clarify the students' perception toward gender, the teacher needs to explain the concept of gender equality. It could be done by adding visual representation of both genders that shows equality in both genders. Another suggestion for teachers is that teachers can modify the learning material from other sources to avoid gender stereotype or bias, (3) the other researchers are expected to study gender representation in ELT textbooks with different aspects analyzed or other gender issues that may exist in ELT textbooks. Besides, further researchers can take different aspect i.e political representation, ethnicity, or culture.

\section{REFERENCES}

Ahmad, M., \& Shah, S., K. (2019). A Critical Discourse Analysis of Gender Representations in the Content of 5th Grade English Language Textbook. International and Multidisciplinary Journal of Social Sciences, 8(1), 1-24. doi: 10.17583/rimcis.2019.3989.

Al-Qatawneh, S., \& Al-Rawashdeh, A. (2019). Gender representation in the Arabic language textbook for the ninth grade approved by the 
Ministry of Education for use in schools in the United Arab Emirates (UAE). Studies in Educational Evaluation, 60, 90-98. https://doi.org/10.1016/j.stueduc.2018.12.001

Amerian, M., \& Esmaili, F. (2015). Language and Gender: A Critical Discourse Analysis on Gender Representation in a Series of International ELT Textbooks. International Journal of Research Studies

Education, 4(2), 3-12. doi: 10.5861/ijrse.2014.963.

Bell, M., McCarthy, M., \& McNamara, S. (2006). Variations in Language Use Across Gender. Retrieved fromhttp://csep.psyc.memphis.edu/mcnamara/pdf/Bellgender28 CogSci.pdf

Chick, K., A. (2006). Gender Balance in K-12 American History Textbooks. Social Studies Research and Practice, 1(3), 284-290

Dahmardeh, M., \& Kim, S., D. (2019). Gender Representation in Iranian English language Coursebooks. English Today,111.https://doi.org/10.1017/S0266078419000117

Damayanti, I., L. (2014). Gender Construction on Visual Images in Textbook for Primary School Students. International Journal of Applied Linguistic, 3(2), 100-116.

EDC. (2007). Building A Gender Friendly School Environment. Edication International. 
Fahriany, F., Alek, A., \& Wekke, I. S. (2019). Gender Representation in English Textbooks for Islamic Junior High School Students. Kafa'ah: Journal of Gender Studies, 8(2), 149-168-168. https://doi.org/10.15548/jk.v8i2.221

Foroutan, Y. (2012). Gender Representation in School Textbooks in Iran: The Place of Languages. Current Sociology 60 (6): 771-787.

Salami, A., \& Ghajarieh, A. (2016). The Gendered Discourse of 'Equal Opportunities For Men And Women' In Iranian EFL Textbooks. Gender in Management: An International Journal, 31(2), 114-133. https://doi.org/10.1108/GM-04-2015-0036

Gupta, A., F. \& Lee S., Y., A. (1990). Gender Representation in English Textbooks Used in the Singapore Primary Schools. Language and Education, 4:1, 29-50.

Hall, S.(1997). Representation Cultural Representations and Signifying Practice, London: The Open University, 1.

Holmes, J., \& Miriam M. (2003). The Handbook of Language and Gender, Oxford: Blackwell Publishing.

Lakoff, R. (1973). Language and Women's Place. Language in Society, 2(1): $45-80$

Landis, J. R., \& Koch, G. G. (1977). The Measurement of Observer Agreement for Categorical Data. Biometrics, 33(1), 159. https://doi.org/10.2307/2529310

Lee, J., F.,K. (1999). Acceptability and Usage in Australian English and Hong Kong English. Unpublished PhD thesis, the University of New South Wales. 
Lee, J. F. K. (2006). Gender Representation in Hong Kong English Textbooks.

Retrieved from

http://www.eoc.org.hk/eoc/upload/2006711112336211184.pdf

Lee, J., F., K., \& Collins, P. (2008). "Gender Voices in Hong Kong English Textbooks - Some Past and Current Practices.” Sex Roles 59 (1/2): $127-137$.

Lee, J. F. K., \& Collins, P. (2009). “Australian English-Language Textbooks: The Gender Issues." Gender and Education 21 (4): 353-370.

Lee, J. F. K., \& Collins, P. (2010). "Construction of Gender: A Comparison of Australian and Hong Kong English Language Textbooks.” Journal of Gender Studies 19 (2): 121-137.

Lee, F., K. (2012). Gender Study of Hong Kong Secondary English-Language Textbooks. In Empirical Research on Gender Equity Education in Hong Kong, edited by P. K. Choi and K. W. Chan, 3-23. Hong Kong: City University of Hong Kong Press.

Lee, J., F., K. (2014). A Hidden Curriculum in Japanese EFL Textbooks: Gender representation. Linguistics and Education, 27, 39-53. https://doi.org/10.1016/j.linged.2014.07.002

Lee, J., F., K. (2016). Gender Representation in Japanese EFL Textbooks - a corpus study, Gender and Education, https://doi.org/10.1080/09540253.2016.1214690

LeMoyne, R. (2011). Promoting Gender Equality:An Equity-based Approach to Programming. 
Marshall, C., \& G.B. Rossman. (2006). Designing Qualitative Research (4 ${ }^{\text {th }}$ edition). Caliornia: Sage Publication Inc.

Matsumoto, D.,\& Juang, L. (2008). Culture and Psychology. Wadsworth: Cengage Learning, $4^{\text {th }}$ edition.

Mustapha, S. (2012). Gender Equality in and through Education in Nigeria: Gender Representation in Learning Materials. Project Report.

Naufal, Q. (2015). Gender Representation in English Language Textbook. American Journal of Educational Science.

Porreca, K., L. (1984). 'Sexism in Current ESL Textbooks.' TESOL Quarterly, 18(4), 704-724

Sadker, M., Sadker, D., \& Klein, S. (1991). Chapter 7: The Issue of Gender in Elementary and Secondary Education. Review of Research in Education, 17(1), 269-334. doi:10.3102/0091732x017001269

Tarrayo, V. (2014). Gendered World Sexism in Philippine Preschool English language textbooks. Journal on English Language Teaching, 4(2), 25-32

Tomlison, B. (1998). Materials Development in Language Teaching. Cambridge: Cambridge University press

UNESCO. (2015). A Guide for Gender Equality in Teacher Education Policy and Practices. Paris: UNESCO

United Nations of Human Rights. (2014). Gender Stereotypes and Stereotyping and Women's Rights. 
REGISTER JOURNAL

Vol. 13, No. 1, (2020), pp.183-207

p-ISSN: 1979-8903 ; e-ISSN : 2503-O40X

Website: http://journalregister.iainsalatiga.ac.id/index.php/register/

Wu, H., \& Liu, H., L.(2015). Gender Representation in Primary English Textbooks in Mainland China 1978 to 2003. International Journal of Humanities and Social Science, Vol 5, No 6.

Yang, C., C,. R. (2011). Gender Representation in a Hong Kong Primary English Textbook Series: The Relationship between Language Planning and Social Policy. Current Issues in Language Planning 12 (1): 77-88. 